\title{
PENERAPAN ANALISIS REGRESI MULTIVARIAT UNTUK MENGANALISIS FAKTOR-FAKTOR YANG MEMPENGARUHI PERSENTASE UNDERWEIGHT DAN STUNTING DI INDONESIA
}

\author{
DWI MALAHAYATI, IZZATI RAHMI HG, HAZMIRA YOZZA \\ Program Studi S1 Matematika, \\ Fakultas Matematika dan Ilmu Pengetahuan Alam, Universitas Andalas, \\ Kampus UNAND Limau Manis Padang, Indonesia. \\ email : dwimalahayati39@gmail.com
}

Diterima 22 Juni 2019 Direvisi 6 Juli 2019 Dipublikasikan 4 Agustus 2019

\begin{abstract}
Abstrak. Status gizi merupakan faktor penting yang mempengaruhi derajat kesehatan. Masalah gizi utama yang dihadapi Indonesia saat ini adalah kejadian balita underweight dan stunting. Untuk menanggulangi masalah underweight dan stunting ini, pemerintah membuat beberapa program gizi dan sudah dilaksanakan secara menyeluruh dan kontinu di Indonesia. Namun, program tersebut belum memberikan hasil yang optimal. Oleh karena itu, perlu dianalisis program gizi yang berpengaruh signifikan terhadap persentase underweight dan stunting pada balita di Indonesia. Proses analisis dilakukan dengan menggunakan analisis regresi multivariat. Berdasarkan hasil analisis yang dilakukan, maka dapat disimpulkan bahwa program gizi yang berpengaruh signifikan terhadap persentase underweight dan stunting pada balita di Indonesia adalah persentase bayi mendapat ASI eksklusif, persentase balita kurus mendapat makanan tambahan, persentase ibu hamil risiko KEK, persentase wanita usia subur risiko KEK, dan persentase rumah tangga mengonsumsi garam beriodium.
\end{abstract}

Kata Kunci: Underweight, Stunting, Program Gizi, Analisis Regresi Multivariat

\section{Pendahuluan}

Status gizi merupakan faktor penting yang mempengaruhi derajat kesehatan. Status gizi yang baik dapat membantu proses pertumbuhan dan perkembangan anak. Permasalahan yang terjadi di Indonesia sampai sekarang adalah kasus gizi buruk pada balita yang masih tergolong parah, dimana Indonesia menempati urutan ke-108 di dunia dengan kasus gizi buruk terbanyak.

Masalah gizi utama yang dihadapi Indonesia saat ini adalah kejadian balita underweight dan stunting. Berdasarkan data Pemantauan Status Gizi Indonesia tahun 2017, masalah gizi balita di Indonesia masih tinggi, yaitu 17,8\% untuk kasus underweight dan 29,6\% untuk kasus stunting. Berdasarkan standar WHO, suatu wilayah dikatakan baik jika persentase underweight $<10 \%$ dan stunting $<20 \%$. Oleh karena itu, perlu dilakukan upaya-upaya untuk mengatasi masalah under- 
weight dan stunting pada balita di Indonesia. Salah satunya dengan mendeteksi indikator program gizi yang menjadi peubah penciri pada underweight dan stunting. Salah satu metode yang dapat digunakan untuk memodelkan pengaruh indikator program gizi terhadap persentase underweight dan stunting adalah analisis regresi multivariat.

\section{Landasan Teori}

\subsection{Status Gizi}

Status gizi merupakan suatu ukuran mengenai kondisi tubuh seseorang yang dapat dilihat dari makanan yang dikonsumsi dan penggunaan zat-zat gizi di dalam tubuh. Salah satu penilaian status gizi didasarkan pada Berat Badan menurut Umur $(\mathrm{BB} / \mathrm{U})$. Berdasarkan indikator BB/U, status gizi dibagi menjadi gizi buruk, gizi kurang, gizi baik, dan gizi lebih. Gabungan antara gizi buruk dan gizi kurang disebut dengan underweight. Selain indikator $\mathrm{BB} / \mathrm{U}$, penilaian status gizi juga didasarkan pada Tinggi Badan menurut Umur (TB/U). Berdasarkan indikator TB/U, status gizi dibagi menjadi sangat pendek, pendek, dan normal. Seorang anak yang gagal tumbuh akibat kekurangan gizi kronis, sehingga tinggi anak terlalu pendek untuk usianya disebut stunting.

\subsection{Analisis Regresi Multivariat}

Analisis regresi multivariat merupakan analisis regresi yang dilakukan apabila terdapat lebih dari satu variabel respon. Jika terdapat variabel respon sebanyak $q$ dan variabel prediktor sebanyak $p$, maka model regresi multivariat untuk pengamatan ke- $i$ respon ke- $j$ adalah [4]:

$$
\begin{aligned}
Y_{i 1} & =\beta_{01}+\beta_{11} X_{i 1}+\beta_{21} X_{i 2}+\cdots+\beta_{p 1} X_{i p}+\epsilon_{i 1}, \\
Y_{i 2} & =\beta_{02}+\beta_{12} X_{i 1}+\beta_{22} X_{i 2}+\cdots+\beta_{p 2} X_{i p}+\epsilon_{i 2}, \\
\vdots & \\
Y_{i q} & =\beta_{0 q}+\beta_{1 q} X_{i 1}+\beta_{2 q} X_{i 2}+\cdots+\beta_{p q} X_{i p}+\epsilon_{i q} .
\end{aligned}
$$

Model regresi multivariat yang terdiri atas $q$ model linear secara simultan dapat ditunjukkan secara matriks dalam persamaan :

$$
\mathbf{Y}_{(n \times q)}=\mathbf{X}_{n \times(p+1)} \boldsymbol{\beta}_{(p+1) \times q}+\boldsymbol{\epsilon}_{(n \times q)} .
$$

Estimasi kuadrat terkecil dari $\hat{\boldsymbol{\beta}}$ sebagai berikut [5]:

$$
\hat{\boldsymbol{\beta}}=\left(\mathbf{X}^{T} \mathbf{X}\right)^{-1} \mathbf{X}^{T} \mathbf{Y} .
$$

\subsubsection{Pengujian Korelasi Antar Variabel Respon}

Variabel $Y_{1}, Y_{2}, \cdots, Y_{q}$ dikatakan saling berkorelasi jika antar variabel respon bersifat tidak saling bebas. Untuk menguji kebebasan antar variabel respon dapat menggunakan uji Bartlett Spericity dengan hipotesis :

$H_{0}$ : Antar variabel respon bersifat saling bebas,

$H_{1}$ : Antar variabel respon bersifat tidak saling bebas, 
dimana $q$ adalah banyak variabel respon dan $\boldsymbol{R}$ adalah matriks korelasi dari semua variabel respon. Statistik uji yang digunakan adalah

$$
\chi_{\text {hitung }}^{2}=-\left\{n-1-\frac{2 q+5}{6}\right\} \ln |\boldsymbol{R}| .
$$

$H_{0}$ akan ditolak jika $\chi_{\text {hitung }}^{2}>\chi_{\alpha, \frac{1}{2} q(q-1)}^{2}$, artinya antar variabel respon bersifat tidak saling bebas. Ini berarti antar variabel respon saling berkorelasi sehingga dapat digunakan analisis regresi multivariat.

\subsubsection{Pengujian Multikolinearitas}

Model regresi multivariat yang baik seharusnya tidak terjadi multikolinearitas. Deteksi ada atau tidaknya multikolinearitas di dalam model regresi multivariat dapat dilihat dari besaran VIF (Variance Inflation Factor) dan tolerance. Nilai VIF ditentukan dengan rumus sebagai berikut :

$$
V I F=\frac{1}{\text { Tolerance }} .
$$

Regresi multivariat bebas dari multikolinearitas jika besar nilai VIF $<10$ dan nilai tolerance $>0,10[2]$.

\subsubsection{Kullback's Information Criterion Corrected (KICc)}

Pemilihan model regresi multivariat dapat menggunakan kriteria KICc (Kullbacks Information Criterion Corrected). Kriteria pemilihan model terbaik metode ini adalah model dengan nilai KICc terkecil di antara semua kemungkinan model. Nilai KICc ditentukan dengan rumus sebagai berikut [3]:

$$
K I C c=n(\ln |\hat{\boldsymbol{\Sigma}}|+q)+\frac{d(3 n-p-q-1)}{n-p-q-1}
$$

dengan:

$$
\begin{aligned}
d & =q p+0,5 q(q+1) \\
q & =\text { banyak variabel respon, } \\
p & =\text { banyak variabel prediktor, } \\
n & =\text { banyak pengamatan, } \\
\hat{\mathbf{\Sigma}} & =\text { estimasi matriks varian-kovarian galat (error) } .
\end{aligned}
$$

\subsection{Pengujian Signifikansi Model}

\subsubsection{Pengujian Signifikansi Model Secara Serentak}

Hipotesis yang digunakan pada pengujian ini adalah:

$$
\begin{aligned}
& H_{0}: \beta_{k j}=0, k=1,2, \cdots, p, j=1,2, \cdots, q, \\
& H_{1}: \text { paling sedikit ada satu } \beta_{k j} \neq 0 .
\end{aligned}
$$


Statistik uji yang digunakan adalah

$$
V_{\text {hitung }}=-\left[(n-1)-\frac{p+q+1}{2}\right] \ln \Lambda,
$$

dimana besaran Wilk's Lambda didefinisikan sebagai berikut :

$$
\Lambda=\frac{\left|\mathbf{Y}^{T} \mathbf{Y}-\hat{\boldsymbol{\beta}} \mathbf{X}^{T} \mathbf{Y}\right|}{\left|\mathbf{Y}^{T} \mathbf{Y}-n \overline{\mathbf{y}} \overline{\mathbf{y}}^{T}\right|},
$$

dengan $\overline{\mathbf{y}}$ adalah vektor rata-rata variabel respon. $H_{0}$ ditolak jika $V_{\text {hitung }}>\chi_{v=p q}^{2}$, artinya ada parameter yang tidak sama dengan nol sehingga model signifikan [1].

\subsubsection{Pengujian Signifikansi Model Secara Parsial}

Setiap variabel prediktor $X_{k} ; k=1,2, \ldots, p$ akan dilakukan pengujian untuk melihat pengaruh setiap variabel prediktor terhadap variabel respon secara parsial. Hipotesis yang digunakan adalah :

$$
\begin{aligned}
& H_{0}: \beta_{k j}=0, j=1,2, \cdots, q, \\
& H_{1}: \beta_{k j} \neq 0, j=1,2, \cdots, q .
\end{aligned}
$$

Statistik uji dan kriteria uji yang digunakan sama seperti pengujian secara serentak, tetapi pada pengujian ini hanya untuk menguji variabel terpilih secara parsial [4].

\subsection{Pengujian Asumsi}

\subsubsection{Pengujian Kesamaan Matriks Ragam Peragam Galat}

Pengujian asumsi kesamaan matriks ragam peragam galat dilakukan dengan menggunakan uji Box M. Pada pengujian ini data dibagi menjadi beberapa kelompok. Hipotesis yang digunakan adalah :

$$
\begin{aligned}
& H_{0}: \boldsymbol{\Sigma}_{1}=\boldsymbol{\Sigma}_{2}=\cdots=\boldsymbol{\Sigma}_{k}, \\
& H_{1}: \boldsymbol{\Sigma}_{i} \neq \boldsymbol{\Sigma}_{j} \text { untuk } i \neq j .
\end{aligned}
$$

Statistik uji yang digunakan adalah [4]:

$$
\chi_{\text {hitung }}^{2}=(1-c) M \text {, }
$$

dengan :

$$
\begin{aligned}
M & =\left[\sum_{i=1}^{k}\left(n_{i}-1\right)\right] \ln |\mathbf{S}|-\sum_{i=1}^{k}\left(n_{i}-1\right) \ln \left|\mathbf{S}_{\mathbf{i}}\right| \\
\mathbf{S} & =\frac{1}{\sum_{i=1}^{k}\left(n_{i}-1\right)} \sum_{i=1}^{k}\left(n_{i}-1\right) \mathbf{S}_{\mathbf{i}} \\
c & =\left[\frac{2 q^{2}+3 q-1}{6(q+1)(k-1)}\right]\left[\sum_{i=1}^{k} \frac{1}{n_{i}-1}-\frac{1}{\sum_{i=1}^{k}\left(n_{i}-1\right)}\right]
\end{aligned}
$$


dimana :

$\mathbf{S}_{\mathbf{i}}$ : Matriks ragam peragam untuk kelompok ke $-i, i=1,2, \cdots, k$,

$n_{i}$ : Ukuran contoh kelompok ke $-i$,

S : Matriks kombinasi ragam peragam dan gabungan dari setiap kelompok,

$k$ : banyak kelompok,

$q$ : banyak variabel galat.

$H_{0}$ akan diterima jika $\chi_{\text {hitung }}^{2} \leq \chi_{\alpha, \frac{1}{2}(k-1) q(q+1)}^{2}$. Hal ini berarti matriks ragam peragam galat dari $k$ kelompok adalah sama (homogen) [1].

\subsubsection{Pengujian Kenormalan Galat}

Pengujian normal multivariat pada galat dilakukan dengan hipotesis sebagai berikut.

$$
\begin{aligned}
& H_{0} \text { : galat terdistribusi normal multivariat, } \\
& H_{1} \text { : galat tidak terdistribusi normal multivariat. }
\end{aligned}
$$

Statistik uji yang digunakan adalah

$$
d_{i}^{2}=\left(\mathbf{e}_{i}-\overline{\mathbf{e}}\right)^{T} \mathbf{S}^{-1}\left(\mathbf{e}_{i}-\overline{\mathbf{e}}\right), i=1,2, \cdots, n,
$$

dimana:

$$
\begin{aligned}
& \mathbf{e}_{i} \text { : vektor sisaan pengamatan ke }-i, \\
& \overline{\mathbf{e}}: \text { vektor rata-rata sisaan, } \\
& \mathbf{S}^{-1}: \text { invers matriks kovarian sisaan berukuran } q \times q .
\end{aligned}
$$

Jika dari sampel berukuran $n$ terdapat lebih dari $\frac{1}{2} n$ sampel yang memenuhi kondisi $d_{i}^{2} \leq \chi_{\frac{1}{2}, q}^{2}$, maka $H_{0}$ diterima [1].

\section{Metode Penelitian}

\subsection{Data Penelitian}

Penelitian ini menggunakan data sekunder yang diperoleh dari hasil Pemantauan Status Gizi tahun 2017 yang dilaksanakan oleh Direktorat Gizi Masyarakat Direktorat Jenderal Kesehatan Masyarakat Kementerian Kesehatan. Dalam penelitian ini, pengamatan dilakukan terhadap 458 kabupaten/kota yang ada di Indonesia.

\subsection{Variabel Penelitian}

Variabel respon yang digunakan dalam penelitian adalah persentase underweight $\left(Y_{1}\right)$ dan stunting $\left(Y_{2}\right)$. Adapun variabel prediktor yang digunakan adalah persentase bayi mendapat ASI eksklusif $\left(X_{1}\right)$, persentase balita mendapat kapsul vitamin A $\left(X_{2}\right)$, persentase balita kurus mendapat makanan tambahan $\left(X_{3}\right)$, persentase balita ditimbang 4 kali atau lebih dalam 6 bulan terakhir $\left(X_{4}\right)$, persentase ibu hamil risiko KEK $\left(X_{5}\right)$, persentase wanita usia subur risiko $\mathrm{KEK}\left(X_{6}\right)$, persentase ibu hamil risiko KEK mendapat makanan tambahan $\left(X_{7}\right)$, dan persentase rumah tangga mengonsumsi garam beriodium $\left(X_{8}\right)$. 


\subsection{Metode Analisis}

Metode analisis yang digunakan dalam penelitian sebagai berikut.

(1) Mendeskripsikan data variabel respon dan variabel prediktor secara umum.

(2) Menguji korelasi antar variabel respon.

(3) Melakukan pengujian multikolinearitas.

(4) Melakukan analisis regresi multivariat dengan langkah-langkah:

(a) Membentuk semua kemungkinan model.

(b) Menghitung nilai KICc untuk setiap kemungkinan model.

(c) Melakukan pemilihan model terbaik.

(d) Melakukan pengujian signifikansi model regresi multivariat.

(e) Melakukan pengujian asumsi kesamaan matriks ragam peragam dan kenormalan galat.

(f) Menganalisis faktor-faktor yang berpengaruh signifikan terhadap persentase underweight dan stunting di Indonesia.

\section{Pembahasan}

\subsection{Korelasi Antar Variabel Respon}

Jika menggunakan uji Bartlett Spericity hasilnya dapat dilihat sebagai berikut dengan hipotesis :

$$
\begin{aligned}
& H_{0} \text { : Antar variabel respon bersifat saling bebas, } \\
& H_{1} \text { : Antar variabel respon bersifat tidak saling bebas. }
\end{aligned}
$$

Statistik uji yang diperoleh:

$$
\chi_{\text {hitung }}^{2}=330,095 \text {. }
$$

Karena $\chi_{\text {hitung }}^{2}$ lebih besar dari $\chi_{0,05 ; 1}^{2}$ sebesar 3,841 maka disimpulkan tolak $H_{0}$, yang artinya antar variabel respon bersifat tidak saling bebas. Ini berarti antar variabel respon saling berkorelasi sehingga dapat digunakan analisis regresi multivariat.

\subsection{Pengujian Multikolinearitas}

Hasil uji multikolinearitas dapat dilihat pada Tabel 1.

Karena semua variabel prediktor memiliki nilai VIF $<10$ dan nilai tolerance $>$ 0,10 maka dapat disimpulkan bahwa tidak terdapat gejala multikolinearitas antar variabel prediktor, sehingga dapat digunakan analisis regresi multivariat.

\subsection{Pembentukan Model Regresi Multivariat Tahap I}

\subsubsection{Pemilihan Model Terbaik}

Pemilihan model terbaik menggunakan kriteria KICc yang nilainya diperoleh dengan software Minitab menggunakan persamaan (2.5). Hasilnya dapat dilihat pada Tabel 2. Berdasarkan Tabel 2 diperoleh model terbaik dengan satu variabel prediktor sampai delapan variabel prediktor seperti yang terlihat pada Tabel 3. 
Tabel 1. Hasil Uji Multikolinearitas

\begin{tabular}{|c|c|c|}
\hline \multirow{2}{*}{ Model } & \multicolumn{2}{c|}{ Collinearity Statistics } \\
\cline { 2 - 3 } & Tolerance & VIF \\
\hline Persentase bayi mendapat ASI eksklusif $\left(X_{1}\right)$ & 0,877 & 1,140 \\
\hline Persentase balita mendapat kapsul vitamin A $\left(X_{2}\right)$ & 0,581 & 1,723 \\
\hline Persentase balita kurus mendapat makanan tambahan $\left(X_{3}\right)$ & 0,729 & 1,372 \\
\hline Persentase balita ditimbang 4 kali atau lebih dalam 6 bulan terakhir $\left(X_{4}\right)$ & 0,528 & 1,894 \\
\hline Persentase ibu hamil risiko KEK $\left(X_{5}\right)$ & 0,421 & 2,377 \\
\hline Persentase wanita usia subur risiko KEK $\left(X_{6}\right)$ & 0,409 & 2,445 \\
\hline Persentase ibu hamil risiko KEK mendapat makanan tambahan $\left(X_{7}\right)$ & 0,868 & 1,152 \\
\hline Persentase rumah tangga mengonsumsi garam beriodium $\left(X_{8}\right)$ & 0,961 & 1,041 \\
\hline
\end{tabular}

Tabel 2. Hasil Perhitungan KICc dari Semua Kemungkinan Model

\begin{tabular}{|c|c|c|c|c|c|}
\hline No & Prediktor & $\mathrm{KICc}$ & No & Prediktor & $\mathrm{KICc}$ \\
\hline 1 & $X_{1}$ & 4101,19 & 116 & $X_{1} X_{3} X_{6} X_{8}$ & 3985,39 \\
\hline 2 & $X_{2}$ & 4100,39 & $\vdots$ & $\vdots$ & $\vdots$ \\
\hline 3 & $X_{3}$ & 4067,32 & 163 & $X_{1} X_{2} X_{3} X_{4} X_{5}$ & 4023,08 \\
\hline 4 & $X_{4}$ & 4111,27 & $\vdots$ & $\vdots$ & $\vdots$ \\
\hline$\vdots$ & $\vdots$ & $\vdots$ & 190 & $X_{1} X_{3} X_{5} X_{6} X_{8}$ & 3985,68 \\
\hline 9 & $X_{1} X_{2}$ & 4093,19 & $\vdots$ & $\vdots$ & $\vdots$ \\
\hline$\vdots$ & $\vdots$ & $\vdots$ & 219 & $X_{1} X_{2} X_{3} X_{4} X_{5} X_{6}$ & 4010,44 \\
\hline 24 & $X_{3} X_{6}$ & 4019,73 & $\vdots$ & $\vdots$ & $\vdots$ \\
\hline$\vdots$ & $\vdots$ & $\vdots$ & 238 & $X_{1} X_{3} X_{5} X_{6} X_{7} X_{8}$ & 3789,02 \\
\hline 37 & $X_{1} X_{2} X_{3}$ & 4062,75 & $\vdots$ & $\vdots$ & $\vdots$ \\
\hline$\vdots$ & $\vdots$ & $\vdots$ & 247 & $X_{1} X_{2} X_{3} X_{4} X_{5} X_{6} X_{7}$ & 4014,14 \\
\hline 45 & $X_{1} X_{3} X_{6}$ & 4000,38 & $\vdots$ & $\vdots$ & $\vdots$ \\
\hline$\vdots$ & $\vdots$ & $\vdots$ & 253 & $X_{1} X_{3} X_{4} X_{5} X_{6} X_{7} X_{8}$ & 3994,65 \\
\hline 93 & $X_{1} X_{2} X_{3} X_{4}$ & 4060,87 & 254 & $X_{2} X_{3} X_{4} X_{5} X_{6} X_{7} X_{8}$ & 4020,28 \\
\hline$\vdots$ & $\vdots$ & : & 255 & $X_{1} X_{2} X_{3} X_{4} X_{5} X_{6} X_{7} X_{8}$ & 4000,35 \\
\hline
\end{tabular}

Berdasarkan Tabel 3 terlihat bahwa nilai KICc terkecil adalah 3789,02 yaitu model dengan variabel prediktor $X_{1}, X_{3}, X_{5}, X_{6}, X_{7}, X_{8}$. Persamaan model regresi 
Tabel 3. Model Terbaik Untuk Setiap Banyak Variabel Prediktor yang Digunakan

\begin{tabular}{|c|l|c|}
\hline Banyak Variabel & Variabel pada Model Terbaik & KICc \\
\hline 1 & $X_{3}$ & 4067,32 \\
\hline 2 & $X_{3} X_{6}$ & 4019,73 \\
\hline 3 & $X_{1} X_{3} X_{6}$ & 4000,38 \\
\hline 4 & $X_{1} X_{3} X_{6} X_{8}$ & 3985,39 \\
\hline 5 & $X_{1} X_{3} X_{5} X_{6} X_{8}$ & 3985,68 \\
\hline 6 & $X_{1} X_{3} X_{5} X_{6} X_{7} X_{8}$ & $\mathbf{3 7 8 9 , 0 2}$ \\
\hline 7 & $X_{1} X_{3} X_{4} X_{5} X_{6} X_{7} X_{8}$ & 3994,65 \\
\hline 8 & $X_{1} X_{2} X_{3} X_{4} X_{5} X_{6} X_{7} X_{8}$ & 4000,35 \\
\hline
\end{tabular}

multivariat yang terbentuk adalah sebagai berikut :

$$
\begin{aligned}
& Y_{1}=27,655-0,090 X_{1}-0,069 X_{3}+0,128 X_{5}+0,293 X_{6}+0,017 X_{7}-0,078 X_{8} \\
& Y_{2}=36,646-0,058 X_{1}-0,081 X_{3}+0,031 X_{5}+0,345 X_{6}+0,027 X_{7}-0,048 X_{8} .
\end{aligned}
$$

\subsubsection{Pengujian Signifikansi Model}

(1) Pengujian Signifikansi Model Secara Serentak.

Dalam pengujian signifikansi model secara serentak digunakan hipotesis sebagai berikut.

$$
\begin{aligned}
& H_{0}: \beta_{p q}=0 ; p=1,3,5,6,7,8, q=1,2 . \\
& H_{1}: \text { paling sedikit ada satu } \beta_{p q} \neq 0 .
\end{aligned}
$$

Besaran Wilk's Lambda yang diperoleh adalah

$$
\Lambda=0,706 .
$$

Statistik uji V-Bartlett yang diperoleh sebagai berikut.

$$
V_{\text {hitung }}=157,411 \text {. }
$$

Karena $V_{\text {hitung }}$ lebih besar dari $\chi_{0,05 ; 12}^{2}$ sebesar 21,026, maka $H_{0}$ ditolak yang berarti secara serentak, paling tidak ada satu variabel prediktor yang signifikan berpengaruh terhadap variabel respon.

(2) Pengujian Signifikansi Model Secara Parsial.

Pada pengujian ini, masing-masing variabel prediktor diuji terhadap variabel respon secara parsial. Hasil pengujian signifikansi model secara parsial ditampilkan pada Tabel 4 .

Untuk variabel prediktor $X_{1}, X_{3}, X_{5}, X_{6}, X_{8}$ diperoleh $V_{\text {hitung }}>\chi_{0,05 ; 2}^{2}$, maka secara parsial variabel prediktor $X_{1}, X_{3}, X_{5}, X_{6}, X_{8}$ berpengaruh signifikan terhadap variabel respon. Untuk variabel prediktor $X_{7}$ diperoleh $V_{\text {hitung }}<\chi_{0,05 ; 2}^{2}$, maka secara parsial variabel prediktor $X_{7}$ tidak berpengaruh signifikan terhadap variabel respon, sehingga perlu dibentuk model baru dengan menggunakan variabel prediktor yang signifikan. 
Tabel 4. Uji Parsial Enam Variabel Prediktor (Nilai Kritis $\chi_{0,05 ; 2}^{2}=5,99$ )

\begin{tabular}{|c|c|c|}
\hline Prediktor & $\Lambda_{\text {hitung }}$ & $V_{\text {hitung }}$ \\
\hline$X_{1}$ & 0,9635 & 16,92 \\
\hline$X_{3}$ & 0,8948 & 50,57 \\
\hline$X_{5}$ & 0,9376 & 29,30 \\
\hline$X_{6}$ & 0,9175 & 39,17 \\
\hline$X_{7}$ & 0,9899 & $\mathbf{4 , 6 4}$ \\
\hline$X_{8}$ & 0,9541 & 21,39 \\
\hline
\end{tabular}

\subsection{Pembentukan Model Regresi Multivariat Tahap II}

\subsubsection{Modifikasi Model}

Dengan menggunakan variabel prediktor yang signifikan pada Tabel 4 diperoleh model baru yaitu model dengan lima variabel prediktor sebagai berikut.

$$
\begin{aligned}
& Y_{1}=28,169-0,090 X_{1}-0,066 X_{3}+0,126 X_{5}+0,288 X_{6}-0,078 X_{8} \\
& Y_{2}=37,456-0,058 X_{1}-0,075 X_{3}+0,027 X_{5}+0,337 X_{6}-0,048 X_{8} .
\end{aligned}
$$

Jika diperhatikan kembali Tabel 3, dapat diketahui bahwa model ini adalah model terbaik dengan lima variabel prediktor.

\subsubsection{Pengujian Signifikansi Model}

(1) Pengujian Signifikansi Model Secara Serentak.

Dalam pengujian signifikansi model secara serentak digunakan hipotesis sebagai berikut.

$$
\begin{aligned}
& H_{0}: \beta_{p q}=0 ; p=1,3,5,6,8 ; q=1,2 \\
& H_{1}: \text { paling sedikit ada satu } \beta_{p q} \neq 0 .
\end{aligned}
$$

Besaran Wilk's Lambda yang diperoleh adalah

$$
\Lambda=0,710 \text {. }
$$

Statistik uji V-Bartlett yang diperoleh sebagai berikut.

$$
V_{\text {hitung }}=155,203 .
$$

Karena $V_{\text {hitung }}$ lebih besar dari $\chi_{0,05 ; 10}^{2}$ sebesar 18,307, maka $H_{0}$ ditolak yang berarti secara serentak, paling tidak ada satu variabel prediktor yang signifikan berpengaruh terhadap variabel respon.

(2) Pengujian Signifikansi Model Secara Parsial.

Pada pengujian ini, masing-masing variabel prediktor diuji terhadap variabel respon secara parsial. Hasil pengujian signifikansi model secara parsial ditampilkan pada Tabel 5 . 
Tabel 5. Uji Parsial Lima Variabel Prediktor (Nilai Kritis $\chi_{0,05 ; 2}^{2}=5,99$ )

\begin{tabular}{|c|c|c|}
\hline Prediktor & $\Lambda_{\text {hitung }}$ & $V_{\text {hitung }}$ \\
\hline$X_{1}$ & 0,9635 & 16,92 \\
\hline$X_{3}$ & 0,8948 & 50,57 \\
\hline$X_{5}$ & 0,9376 & 29,30 \\
\hline$X_{6}$ & 0,9175 & 39,17 \\
\hline$X_{8}$ & 0,9541 & 21,39 \\
\hline
\end{tabular}

Karena $V_{\text {hitung }}>\chi_{0,05 ; 2}^{2}$ maka dapat disimpulkan bahwa variabel prediktor $X_{1}, X_{3}, X_{5}, X_{6}, X_{8}$ secara parsial berpengaruh signifikan terhadap variabel respon.

\subsection{Pengujian Asumsi}

\subsubsection{Pengujian Asumsi Matriks Ragam Peragam Galat}

Untuk memeriksa asumsi tentang kesamaan matriks ragam peragam galat, maka dirumuskan hipotesis sebagai berikut :

$$
\begin{aligned}
& H_{0}: \boldsymbol{\Sigma}_{1}=\boldsymbol{\Sigma}_{2}, \\
& H_{1}: \boldsymbol{\Sigma}_{1} \neq \boldsymbol{\Sigma}_{2} .
\end{aligned}
$$

Statistik uji:

$$
\chi_{\text {hitung }}^{2}=(1-c) M=3,2752 .
$$

Karena $\chi_{\text {hitung }}^{2}$ lebih kecil dari $\chi_{0,05 ; 3}^{2}$ sebesar 7,81 dapat disimpulkan terima $H_{0}$. Ini berarti matriks ragam peragam dari dua kelompok adalah homogen.

\subsubsection{Pengujian Asumsi Kenormalan Galat}

Pengujian normal multivariat dilakukan dengan hipotesis sebagai berikut :

$$
\begin{aligned}
& H_{0} \text { : galat terdistribusi normal multivariat, } \\
& H_{1} \text { : galat tidak terdistribusi normal multivariat. }
\end{aligned}
$$

Statistik uji :

$$
d_{i}^{2}=\left(\mathbf{e}_{i}-\overline{\mathbf{e}}\right)^{T} \mathbf{S}^{-1}\left(\mathbf{e}_{i}-\overline{\mathbf{e}}\right), i=1,2, \cdots, n .
$$

Nilai khi-kuadrat tabel :

$$
\chi_{\text {tabel }}^{2}=\chi_{\frac{1}{2}, 2}^{2}=1,386 .
$$

Dari 458 pengamatan diperoleh 240 pengamatan atau $52,40 \%$ dengan kondisi $d_{i}^{2} \leq$ 1,386, maka disimpulkan $H_{0}$ diterima sehingga galat dikatakan terdistribusi normal multivariat. 


\subsection{Analisis Faktor}

Berdasarkan hasil pembentukan model regresi, pengujian signifikansi parameter dan pengujian asumsi diperoleh lima program gizi yang berpengaruh signifikan terhadap persentase underweight $\left(Y_{1}\right)$ dan stunting $\left(Y_{2}\right)$ pada balita di Indonesia, yaitu persentase bayi mendapat ASI eksklusif $\left(X_{1}\right)$, persentase balita kurus mendapat makanan tambahan $\left(X_{3}\right)$, persentase ibu hamil risiko KEK $\left(X_{5}\right)$, persentase wanita usia subur risiko KEK $\left(X_{6}\right)$, dan persentase rumah tangga mengonsumsi garam beriodium $\left(X_{8}\right)$ dengan model sebagai berikut:

$$
\begin{aligned}
& Y_{1}=28,169-0,090 X_{1}-0,066 X_{3}+0,126 X_{5}+0,288 X_{6}-0,078 X_{8} \\
& Y_{2}=37,456-0,058 X_{1}-0,075 X_{3}+0,027 X_{5}+0,337 X_{6}-0,048 X_{8} .
\end{aligned}
$$

\section{Kesimpulan}

Berdasarkan hasil analisis dan pembahasan yang dilakukan, diperoleh lima program gizi yang berpengaruh signifikan terhadap persentase underweight dan stunting pada balita di Indonesia, yaitu persentase bayi mendapat ASI eksklusif, persentase balita kurus mendapat makanan tambahan, persentase ibu hamil risiko KEK, persentase wanita usia subur risiko KEK, dan persentase rumah tangga mengonsumsi garam beriodium.

\section{Daftar Pustaka}

[1] Gaspers, V. 1992. Teknik Analisis dalam Penelitian Percobaan. Tarsito, Bandung

[2] Ghozali, I. 2006. Analisis Multivariat dengan Program SPSS, Edisi Ke-4. Badan Penerbit Universitas Diponegoro, Semarang

[3] Hafidi, B. and A. Mkhadri. 2006. A Corrected Akaike Criterion Based on Kullback's Symmetric Divergence : Application in Time Series, Multiple and Multivariate Regression. Computational Statistics and Data Analiysis. 50 : 15241550

[4] Johnson,R.A and D.W. Wichern. 2007. Applied Multivariate Statistical Analysis, Sixth Edition. Practice Hall, Jersey

[5] Rencher, A.C.. 2002. Methods of Multivariate Analysis. John Wiley and Sons, New York 